\title{
Updating the failure probability of miter gates based on observation of water levels
}

\section{Thuong Van DANG, Quang Anh MAl, Pablo G. MORATO, Philippe RIGo}

\author{
Department of ArGEnCo/ANAST - University of Liege, Belgium \\ *Corresponding author: thuongdv@tlu.edu.vn
}

Keywords: Fatigue; Miter gate; Probability of failure; Updating failure probability; Inspection

\section{ABSTRACT}

Hydraulic steel structures, especially lock gates play a significant role in keeping navigation traffic uninterrupted. After a few decades of operation, many of the welded joints may suffer various degrees of deterioration, primarily due to fatigue. To economically combining crack inspection with a scheduled maintenance of the movable parts of the gate, it is valuable to predict inspection time of the welded joints using the historical operations of the gate, i.e. the variation of water levels. Updating failure probability of welded joint is mature in offshore industry, but it is rarely applied for inland navigation lock gates where low cycle fatigue usually happens. The scope of this paper is to predict the optimum inspection time of a welded joint using the observed water levels of the operational history. The procedure of the present methodology can be found in Fig. 1.

Stresses are calculated for each observed water level by using analytical formulas or finite element method. Each lockage corresponds to a stress cycle. Since water levels in front and behind the gate are not always the same for every lockage due to seasonal flows of the river, the different stress-ranges occurring during the year are represented by an equivalent stress-range value. This equivalent stress-range is used to calculate failure probabilities.

Failure probability of the welded joint is first calculated using a limit state function based on Miner's rule (S-N model) [1] because this cumulative fatigue damage principle is used in the design stage. The S$\mathrm{N}$ curve is taken from EN 1993-1-9. To incorporate the crack inspection results into assessing failure probability, a fracture mechanics (FM) model is used for crack propagation. The most widely used model is the Paris-Erdogan law [2], Eq. (1).

$$
\frac{d a}{d N}=C(\Delta K)^{m}=\mathrm{C}(Y \Delta \sigma \sqrt{\pi a})^{m}
$$

where $\mathrm{N}$ is the number of cycles, $\mathrm{da} / \mathrm{dN}$ is the rate of crack growth, $\mathrm{C}$ and $\mathrm{m}$ are material parameters, $\mathrm{Y}$ is geometry function, $\Delta \sigma$ is the equivalent stress range and $\Delta \mathrm{K}$ is the amplitude of the stress intensity factor.

The FM model is calibrated to reach identical failure probabilities as obtained from the S-N model analysis. The calibration algorithm is carried out by a least-squares fitting in cumulative failure probability space $(\mathrm{Pc})$, as shown in Eq. (2).

$$
\min \sum_{t=1}^{T}\left(P c_{S N}(t)-P c_{F M}\left(t ; x_{1} \ldots x_{N}\right)\right)^{2}
$$

where $P c_{S N}(t)$ is the cumulative failure probability at time $t$, evaluated using the $\mathrm{S}-\mathrm{N}$ model $; P C_{F M}\left(t ; x_{1} \ldots x_{N}\right)$ is the cumulative failure probability at time $\mathrm{t}$, evaluated using FM model with a set of parameters $\left(x_{1} \ldots x_{N}\right)$ representing initial

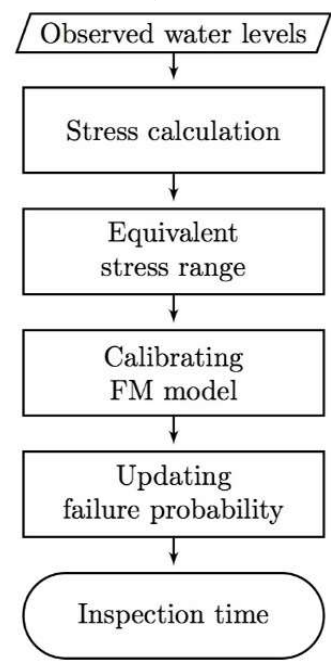

Fig. 1. Updating procedure 
crack size, $\mathrm{C}$, uncertainty of stress range. $\mathrm{T}$ is the service life of the considered structures.

The probability of detection (POD) is used for quantifying the performance of non-destructive testing. POD curves describe the probability that a certain crack size is detected during inspection. In the present paper the POD curves are assumed to be represented by the LogOdds-Log scale model [3]:

$$
\operatorname{POD}(\mathrm{a})=\frac{\alpha a^{\gamma}}{1+\alpha a^{\gamma}}
$$

where $\mathrm{a}(\mathrm{mm})$ is the detectable crack and $\alpha, \gamma$ are regression parameters. To see the effects of POD on the predicted inspection time, three cases of inspection labelled

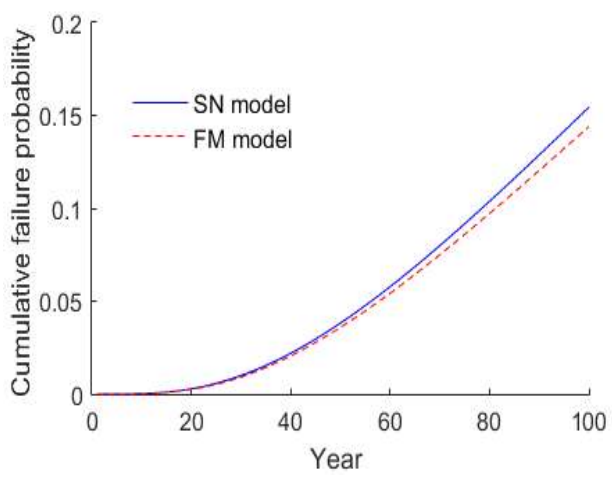

Fig. 2. Calibrated result A $\left(\alpha=0.3 \mathrm{~mm}^{-1}, \gamma=3.0\right), \mathrm{B}\left(\alpha=0.085 \mathrm{~mm}^{-1}, \gamma=3.0\right)$ and $\mathrm{C}\left(\alpha=0.035 \mathrm{~mm}^{-1}, \gamma=3.0\right)$ are used [4].

The simulation method is used to update the failure probability $\left(\mathrm{P}_{\mathrm{f}}\right)$, considering POD and repair policies. It is assumed that all detected cracks are repaired. For the case where crack detected and not repaired, as suggested in [5], it should not be considered in the simulation method as an unrealistically large number of samples is required for updating. The maximum allowable annual probability of failure $\mathrm{P}_{\mathrm{f}}$ $=1.4 \times 10^{-3}$ (equivalent to a target reliability index after 50 years is 1.5 in EN1990) and $90 \%$ probability of detection in three inspection techniques are used.

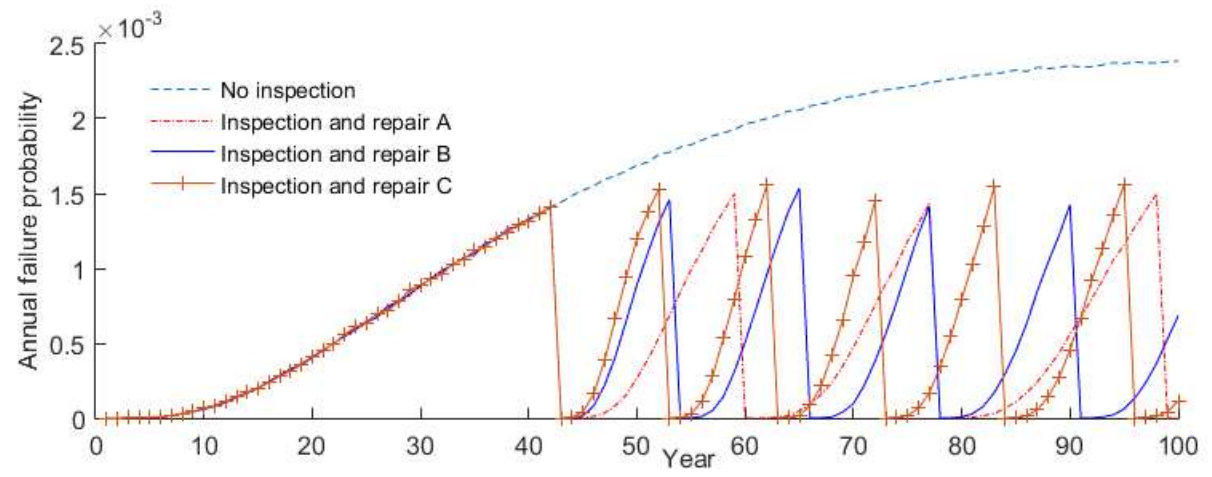

Fig. 3. The updating annual failure probability with $90 \%$ POD in three inspection techniques

The result showed that after about 40 years in service, crack inspection should be done to allow the gate keeping the safety level defined in EN1990 (see Fig. 3.). The crack inspection quality significantly affects the predicted future inspection time. Since the scheduled maintenance of the movable parts is unavoidable, crack inspection should be planned in the design stage to reduce the investment cost.

\section{REFERENCES}

[1] M. A. Miner, "Cumulative damage in fatigue," Am. Soc. Mech. Eng. - J. Appl. Mech., vol. 12, pp. 159-164, 1945.

[2] P. Paris and F. Erdogan, "A Critical Analysis of Crack Propagation Laws,” J. Basic Eng., vol. 85, p. 528, 1963.

[3] A. P. Berens and P. Hovey, "Evaluation of NDE reliability characterization," Dayt. Air Force WrightAeronautical Lab. Wright-Patterson Air Force Base, vol. I, 1981.

[4] S. S. Kulkarni and J. D. Achenbach, "Optimization of inspection schedule for a surface-breaking crack subject to fatigue loading," Probabilistic Eng. Mech., vol. 22, no. 4, pp. 301-312, 2007.

[5] Mai, A. Quang; Sørensen, John D; Philippe, Rigo, "Updating failure probability of a welded joint in offshore wind turbine substructures," in OMAE2016-54232, 2016, pp. 1-10.

\section{ACKNOWLEDGMENTS}

This research is funded by the Wallonie-Bruxelles International (WBI) 